\title{
Review on porphyrins, phthalocyanines and their derivatives as corrosion inhibitors
}

\author{
O.Yu. Grafov* and L.P. Kazansky ${ }^{\dagger}$
}

A.N. Frumkin Institute of Physical Chemistry and Electrochemistry, Russian Academy of

Sciences, Leninsky pr. 31, 119071 Moscow, Russian Federation

*E-mail: grafov.oleg88@gmail.com

\begin{abstract}
The use of porphyrins, phthalocyanines and their derivatives as corrosion inhibitors (CI) is considered in the work. These macromolecules contain four pyrrole rings linked into a flat cycle by four $-\mathrm{CH}=$ groups in the case of porphyrins, and in the case of phthalocyanines, by four $\mathrm{N}=$ atoms. Four pyrrole nitrogen atoms form an inner square that can be occupied by a metal cation. The high inhibitory effect of these macromolecules is explained by their strong chemisorption on the surface of metals. Such adsorption is determined by the planarity of the molecule and a multi-loop conjugated system with lone pair electrons of nitrogen atoms. The $\pi$ electrons of the 16-membered ring can make a large contribution to the $\pi$-interaction. The results of gravimetric measurements, electrochemical studies by the methods of potentiodynamic polarization curves, as well as electrochemical impedance, the main mechanisms of the formation of these thin-layer organic inhibitors of ultrathin (nanoscale) protective layers on the surfaces of different metals in various media, mainly acidic, are discussed. In the given studies, the qualitative composition and structure of the surface adsorption layers were studied using Xray photoelectron and vibrational spectroscopy, and the surface morphology was studied using a scanning electron microscope. Adsorption in solution in situ was studied by reflective ellipsometry with determination of the free energy of adsorption. Attempts to correlate the inhibition efficiency of macrocyclic corrosion inhibitors with the results of quantum chemical calculations were made in a number of studies.
\end{abstract}

Keywords: corrosion, porphyrins, phthalocyanines, polarization curves, electrochemical impedance, scanning electron microscopy XPES, vibrational and optical spectroscopy, ellipsometry, quantum chemistry.

Received: May 13, 2020. Published: June 24, 2020

doi: $\underline{10.17675 / 2305-6894-2020-9-3-2}$

\footnotetext{
${ }^{\dagger}$ Leonid Petrovich Kazansky deceased on May 23, 2020.
} 


\section{Introduction}

Corrosion is a natural phenomenon that is defined as a process in which a material is destroyed due to chemical reactions that occur on its surface a result of interaction with the environment. This phenomenon causes enormous economic and industrial damage due to the fact that many useful properties of materials are deteriorating, appearance is lost, and structures are destroyed.

The application of inhibitors is one of the most effective means of preventing corrosion. Inhibitors are able to adsorb on the metal surface, forming a protective barrier against active compounds that cause the metal corrosion. The efficiency of the inhibitor protection depends on the character of its interaction with the metal surface. Since classical inorganic corrosion inhibitors (chromates, nitrites, salts of heavy metals, etc.) often do not meet environmental safety requirements, interest in using organic compounds as corrosion inhibitors for metals in neutral and acidic media naturally increases [1-7].

Corrosion inhibitors, forming sparingly soluble complexes with ions of a dissolving metal, can also provide high corrosion protection and transfer a metal into a passive state. Such inhibitors of the complexing type are usually divided into two groups: the first one includes heterocyclic compounds containing heteroatoms such as nitrogen, phosphorus, oxygen, sulfur with lone electron pairs and (or) aromatic rings with delocalized $\pi$-electrons that can form insoluble complexes in aqueous solutions, and the second one - consists of metal chelators and complexonates.

The first group includes azoles and their derivatives, for example, 1,2,3-benzotriazole (BTA), which has shown itself as an effective corrosion inhibitor for copper and its alloys [8-10]. The second group includes derivatives of phosphonic acid, such as 1-hydroxyethane-1,1-diphosphonic acid (HEDP), nitrilotrimethylene phosphonic (NTP), ethylenediamine- $N, N, N^{\prime}, N^{\prime}$-tetramethylene phosphonic (EDTP) acids. The use of phosphonates is primarily due to their ability to form thin passivating films on the surface of metals that effectively inhibit atmospheric corrosion [1,10], and phosphonate metal and metal complexonates, especially zinc, can be used in water treatment to protect metals from corrosion in water cooling systems $[11,12]$. This is valid only for alkyl phosphonates, but the acids and their complexes are more widely used in water cooling systems.

The lone electron pairs on heteroatoms or $\pi$-electrons easily participate in the exchange, are able to form a bond and act as nucleophilic centers of inhibitor molecules, greatly facilitating adsorption on a metal whose atoms act as electrophiles. Porphyrins are cyclic aromatic polyamines containing a multi-loop conjugated system, which is based on a 16membered macrocycle with a closed conjugated system, including 4 modified pyrrole subunits, the nitrogen atoms of which form an inner square [13]. The initial structure of all porphyrins is porphin (Fig. 1). Tautomerism arises as a result of an intramolecular jump of two protons and an 18-membered $\pi$-electron ring. Positions 2, 3, 7, 8, 12, 13, 17 and 18 are 
usually designated as $\beta$-positions, respectively, 1, 4, 6, 9, 11, 14, 16 and 19 are referred to as $\alpha$-positions, while 5, 10, 15 and 20 belong to the meso-positions.
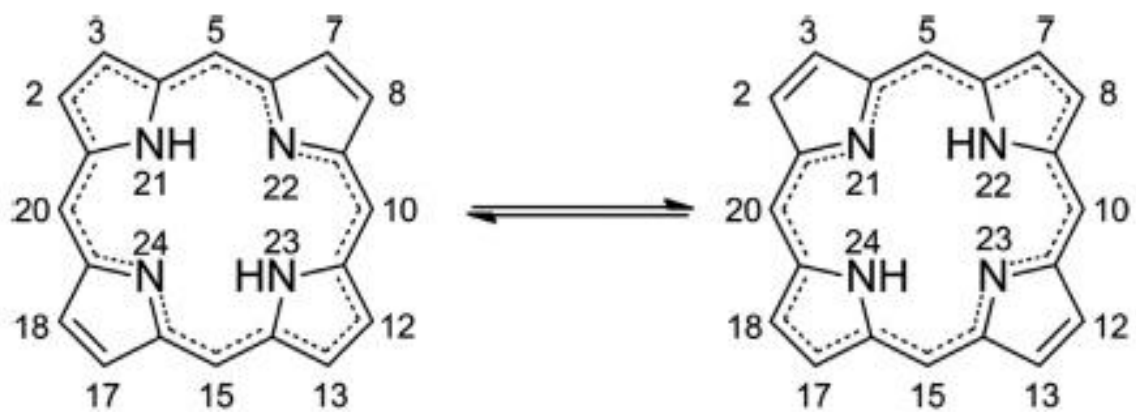

Figure 1. Porphin. Atom numbering according to IUPAC.

Two nitrogen atoms are protonated and are in a trans- position to each other (Fig. 1).

The peripheral hydrogen atoms can be replaced by various radicals. If the mesopositions (C5, C10, C15, C20) are occupied by nitrogen atoms, then it is already mesotetraazoporphin or, in particular, phthalocyanine (Fig. 2b).
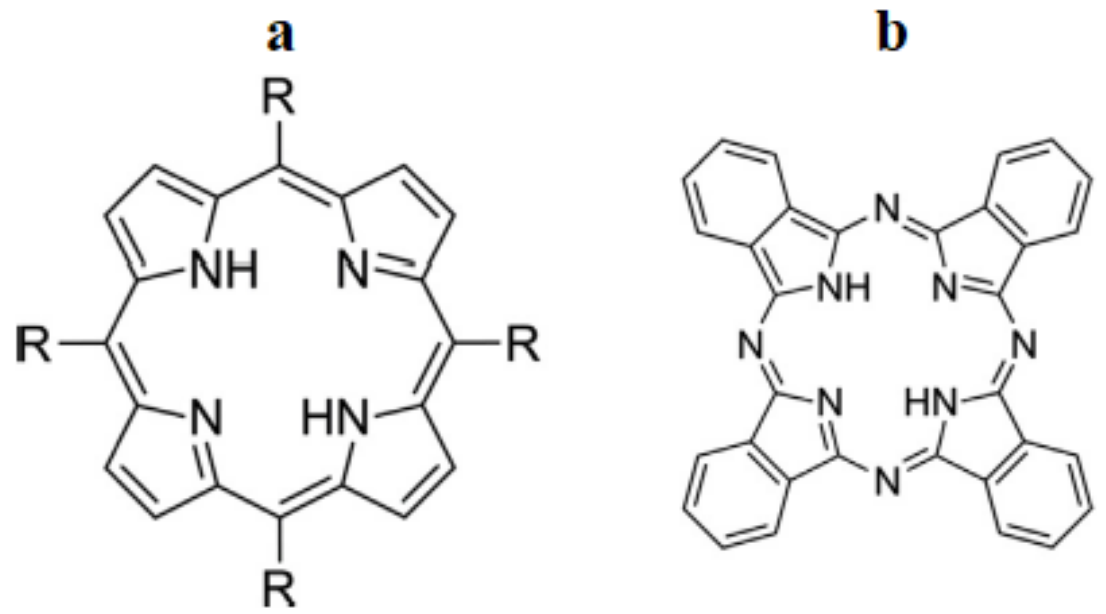

Figure 2. The structure of tetra R-porphyrin (a) and tetrabenzoporphyrazine (phthalocyanine) (b).

Regular porphyrin is insoluble in water and different approaches are used to solubilize them. A recent review examined the methods for producing water-soluble phthalocyanines and porphyrins and their derivatives [14].

During adsorption, the unfilled $d$-shell of the metal can accept the $\pi$-electrons of the porphyrin macro ring or the lone pair of electrons of nitrogen atoms, forming a fairly strong covalent bond. In this case, a very strong protective layer is created on the metal surface. In a recent large review Gottfried [15] has considered the adsorption processes of porphyrins, phthalocyanines and their derivatives on the surface of various materials, including metals. However, there are not so many studies related to the anticorrosive activity of such large 
macromolecules as porphyrins and phthalocyanines, despite the fact that they have many advantages over conventional corrosion inhibitors.

As mentioned above, organic molecules with $\pi$-electron systems and electronegative atoms such as oxygen, nitrogen, sulfur and phosphorus are often used as corrosion inhibitors. It is known that various factors influence the ability of an organic molecule to inhibit metal corrosion: electronic structure, aromaticity, flatness and branching of a molecule. In this regard, macro heterocyclic compounds such as porphyrins and phthalocyanines are of great interest as corrosion inhibitors.

\section{Corrosion inhibition of iron and steels}

Since the 1970s, studies have started on the efficiency of the use of porphyrins and phthalocyanines as corrosion inhibitors for iron in acidic media $[16,17]$, where they have proven themselves well. Aoki et al. [18] had used copper phthalocyanine $(\mathrm{CuPc})$ as a corrosion inhibitor for ASTM-A606-4 steel in 16\% hydrochloric acid. Studies have shown that $\mathrm{CuPc}$ is physically adsorbed on the steel surface and behaves as a mixed type inhibitor, reducing the rate of both the anodic and cathodic reactions. The method of electrochemical impedance had shown that when $1 \mathrm{mM} \mathrm{CuPc}$ is introduced into the solution, the resistance of the double electric layer increases significantly. However, the authors have not calculated and presented achievable degree of protection. Nevertheless, corrosion measurements by weight loss showed that when $C_{\text {inh }}=5 \mathrm{mM}$, the weight loss of the product is significantly reduced, and the degree of protection reaches 94\%. In a similar work [19], the authors studied nickel tetraaminophthalocyanine, which, as shown by spectral data in the UV and visible regions, as well as by IR spectroscopy, voltammetry, and impedance, had formed a polymer protective layer on mild steel by drop-dry method in hydrochloric acid.

A number of metallophthalocyanines based on tetracarboxylate phthalocyanine with various complexing agents, such as $\mathrm{Fe}(\mathrm{III}), \mathrm{Co}(\mathrm{II}), \mathrm{VO}(\mathrm{IV}), \mathrm{Cr}(\mathrm{III}), \mathrm{Si}(\mathrm{IV})$, and $\mathrm{Zn}(\mathrm{II})$, was studied in [20], to protect steel in $1 \% \mathrm{NaCl}$ aqueous solution with $\mathrm{pH}=2$. Of the listed series of metals, the most effective complexes are based on central Co(II) and Fe(III). Polymer phthalocyanine coatings based on Fe(III) polyphthalocyanines resulted in the highest degree of protection of $82 \%$, which is confirmed by the analysis of scanning electrochemical impedance. The polymerization was achieved by simple immersion in a solution with an inhibitor and subsequent heat treatment at $450^{\circ} \mathrm{C}$ in inert atmosphere. It was noted that the inhibition efficiency can be increased to $87 \%$ by introducing a long alkyl chain radical into the phthalocyanine molecule.

A comparative study of the effect on the corrosion behavior of steel in $1.0 \mathrm{M} \mathrm{HCl}$ of phthalocyanine $\left(\mathrm{H}_{2} \mathrm{Pc}\right)$, copper phthalocyanine $(\mathrm{CuPc})$ and tetrasulfuric copper phthalocyanine salt $\left(\mathrm{CuPc}\left(\mathrm{SO}_{3}\right)_{4} \mathrm{Na}_{4}\right)$ in the concentration range from $10^{-5}$ to $10^{-3} \mathrm{~mol} / \mathrm{l}$ is presented in [21, 22]. Polarization studies and studies using the electrochemical impedance method have shown that all the investigated substances behave as inhibitors of a mixed type and, with increasing concentration, the rate of corrosion of steel in solution decreases. From 
the results of the study, it was determined that at the same concentration, the inhibition efficiency decreased in the order $\left(\mathrm{CuPc}\left(\mathrm{SO}_{3}\right)_{4} \mathrm{Na}_{4}\right)>\mathrm{CuPc}>\mathrm{H}_{2} \mathrm{Pc}$. The highest degree of protection reached almost $95 \%$ at a concentration of $10^{-3} \mathrm{~mol} / \mathrm{l}\left(\mathrm{CuPc}\left(\mathrm{SO}_{3}\right)_{4} \mathrm{Na}_{4}\right)$. Based on the data of scanning electron microscopy and energy dispersive X-ray spectroscopy (SEM/EDS), it was concluded that when any of the compounds under study was added, the steel surface was protected by an adsorbed layer of phthalocyanines. Comparing the results of quantum chemical calculations and analysis of degrees of protection, the authors came to the conclusion that the efficiency of inhibition increases with decreasing energy of the lowest unoccupied molecular orbital.

Interesting data were obtained in [23], where the authors modified the surface of steel with copper phthalocyanine for further adsorption on it of a sol gel synthesized from methacryloxypropyltrimethoxysilane (TMSM) and tetraethoxysilane (TEOS) in 1:1 molar ratio. The surface morphology of steel coated with TMSM/TEOS and CuPc was studied using the scanning electron microscope, and the effect of hybrid sol-gel coatings on the behavior of mild steel was studied using polarization curves and the method of electrochemical impedance in the aerated $0.5 \mathrm{M} \mathrm{HCl}$ solution. Self-assembled CuPc films coated with a hybrid gel had shown a strong influence on the corrosion resistance of steel, and when the samples were immersed for 24 hours in the solution with a concentration of $1 \mathrm{mM}$, a degree of protection exceeding $90 \%$ was achieved.

Quraishi and Rawat [24] gave results of the studied tetraphenyldithiaoctaase cyclotetradecane hexane as an inhibitor for steel corrosion in hydrochloric acid solutions of various concentrations. It was shown that direct corrosion tests in $1.0 \mathrm{M} \mathrm{HCl}$ at temperature $t=40^{\circ} \mathrm{C}$ and $C_{\text {inh }}=500 \mathrm{mg} / \mathrm{l}$ the corrosion rate is reduced by $80 \%$, and at room temperature in $3.0 \mathrm{M} \mathrm{HCl}$, a degree of protection of $90 \%$ can be achieved. A similar protective effect persisted in $1.0 \mathrm{M}$ sulfuric acid. The data obtained and the degree of protection were confirmed not only by the gravimetric method, but also by the polarization curves, as well as by the electrochemical impedance method, where a significant increase in charge transfer resistance in the double electric layer was observed. The authors also established the dependence of increase in the inhibitory ability of the molecule with an increase in the number of heteroatoms. Interesting data were also obtained in the study of the combination of the macrocycle with potassium iodide widely used in acidic media, which made it possible to achieve a protective effect of $92 \%$.

Studies of the influence of macro heterocyclic compounds were carried out not only in hydrochloric acid of various concentrations, but also in $\mathrm{H}_{2} \mathrm{SO}_{4}$, another acid important for industry. So in [25], as CI for steel in $0.5 \mathrm{M} \mathrm{H}_{2} \mathrm{SO}_{4}$, copper phthalocyanine, already mentioned above, was studied. The authors determined that this phthalocyanine shows high efficiency and, at a concentration of $1 \mathrm{mM}$, forms a dense protective film on the surface of mild steel. However, the protective effect decreases with increasing temperature to $40^{\circ} \mathrm{C}$, but nevertheless it increases with heating up to $60^{\circ} \mathrm{C}$. Also, studies were carried out by the method of electrochemical impedance on a passive surface of steel, which showed that at 25 
and $40^{\circ} \mathrm{C}$ the corrosion process is controlled by the charge transfer, but at $60^{\circ} \mathrm{C}$ an inductive loop appears, indicating that the corrosion process is under adsorption/desorption control.

Feng et al. [26] investigated the widely used 5,10,15,20-tetraphenylporphyrin (TPP) as an inhibitor for iron corrosion in $0.5 \mathrm{M} \mathrm{H}_{2} \mathrm{SO}_{4}$. The methods used were: polarization curves, electrochemical impedance, as well as X-ray photoelectron (XPE) and infrared (IR) spectroscopies, and scanning electron spectroscopy. The results of XPE and IR spectroscopies showed that TPP is able to form the chemisorbed layers on the iron surface. Electrochemical measurements showed that the degree of protection depends on the time the sample was immersed in the inhibitor solution, and for a longer time it gave a higher degree of protection, for example, $81.3 \%$ with an exposure time of 17 hours. However, a further increase in the exposure time led to a decrease in the protective ability, that, according to the authors, was explained by desorption of TPP molecules.

Another work of these authors [27] presented a comparative study of the rate of formation of adsorption layers on the iron surface of the previously presented tetraphenylporphyrin (TPP) and tetra-(4-chlorophenyl) porphyrin (TClPP) and the effect of the substituent on the degree of protection. From the results of the work it follows that the introduction of chloride helps to accelerate the adsorption of the substance on the surface, but negatively affects the degree of protection. The authors suggest that the presence of the active chloride (electron acceptor) in the composition results in pulling off the electron density from macrocycle. This in turn decreases its interaction with $d$-orbitals of iron, decreasing protective ability of TCIPP in comparison with TPP.

Of great interest is the work of Meyer-Rocher, Siemens and Brockman [28], in which a wide range of both metal and metal-free porphyrins based on tetraphenylporphyrin, with various substituents, as corrosion inhibitors for iron in $5 \% \mathrm{H}_{2} \mathrm{SO}_{4}$, was studied. For all studied substances, an increase in the protective effect was observed, however, porphyrins containing iron showed better results compared to metal-free ones. According to the results of the work, the most promising substituent was an aliphatic hydrophobic group which effect increased with an increase in the carbon chain. Derivatives of TPP were also studied as components of a mixture with epoxy or phenolic resins, and proved to be sufficiently reactive to create strong chemical bonds and form a stable coating.

The inhibitory ability of 5,10,15,20-tetrakis(4-pyridyl)-21H,23H-porphin (TPyP) on the corrosion of mild steel in $5 \% \mathrm{H}_{2} \mathrm{SO}_{4}$ was studied in [29] by the gravimetric method. Moreover, atomic force microscopy is used to examine the surface before and after corrosion tests. The results showed that the presence of TPyP reduces the corrosion rate of steel by more than $50 \%$, and the inhibitory effect of TPyP depends on its concentration and temperature. It follows from the results of atomic force microscopy that uniform smoothing effect was observed during the adsorption of porphin on the steel surface, both before and after corrosion tests. Replacing pyridyl with hydrophenyl [30] also significantly reduces the current density in the active region of potentials. The same authors [31] additionally applied polyaniline on a preformed layer of 5,10,15,20-20-tetra(4-methylphenyl)-21 $\mathrm{H}, 23 \mathrm{H}$ - 
porphyrin to create a protective coating. It turned out that this treatment leads to $80 \%$ protection of mild steel in $0.1 \mathrm{M} \mathrm{H}_{2} \mathrm{SO}_{4}$.

Singh et al. [32] investigated the effects of 5,10,15,20-tetrakis(4-hydroxyphenyl)$21 H, 23 H$-porphyrin (HPTB), 5,10,15,20-tetra(4-pyridyl)-21H,23H-porphyrin (T4PP), 4,4',4"',4"'"-(porphyrin-5,10,15,20-tetrayl)tetrakis(benzoic acid) (THP) and 5,10,15,20tetraphenyl-21H,23H-porphyrin (TPP) on the corrosion of N80 steel in $3.5 \% \mathrm{NaCl}$ solution saturated with $\mathrm{CO}_{2}$ ("sweet solution"). The research results showed that all the macroheterocyclic compounds presented are good corrosion inhibitors for N80 steel, showing a degree of protection in the range from 85 to $91 \%$, and scanning electron microscopy confirmed the formation of protective films of porphyrins on the surface, which prevent the entry of aggressive media to the protected surface. The results obtained were in good agreement with the results of quantum-chemical calculations of the molecules under study.

In another work [33] the inhibitory effect of two heterocyclic porphyrin compounds, namely 5,10,15,20-tetrakis(pentafluorophenyl)-21 $H, 23 H$ palladium(II) porphyrin (PF-1) and 4,4',4"',4"'"-(porphyrin-5,10,15,20-tetrayl)tetrakis(benzoic acid) (PF-2) was investigated in the above medium, but for J55 steel. Using polarization curves, electrochemical impedance, and mass loss, it was found that PF-2 has a greater degree of protection than PF1 , on average, about $93 \%$, at a concentration of $0.4 \mathrm{mM}$. Atomic force microscopy revealed a lower surface roughness after porphyrin adsorption, and measurements of the wettability angle showed that the surface became more hydrophobic. The adsorption of the studied substances proceeded both by physical and chemical mechanisms and was described by the Langmuir adsorption isotherm.

The protective properties of surface films formed by metal-containing porphyrins ( $\mathrm{Zn}$, $\mathrm{Cu}, \mathrm{Co}$ ) on mild steels in $0.5 \mathrm{M} \mathrm{HCl}$ have been investigated by a number of methods [34]. It was shown that the introduction of porphyrins, as well as alkyd resin, significantly shifts the corrosion potential in a positive direction and increases the protective effect, especially in the case of cobalt, up to $98.5 \%$.

Some unusual tin phthalocyanines (4+) were used as corrosion inhibitors for AISI 1018 steel [35] in a brine solution saturated with hydrogen sulfide. A number of methods have shown that phthalocyanine forms a film on the surface, which protection efficiency reaches $87 \%$. The structure of tin phthalocyanines in which the tin cation does not enter the plane of the ring but is located in the center of the antiprism. The X-ray diffraction method had shown that four nitrogen atoms form the bottom of the square antiprism, and the oxygen atoms of the carboxyl groups form the lid. Similar phthalocyanines of tin (IV) bicarboxylates were deposited using a microwave source [36]. It has been shown that corrosion resistance is higher for compounds with a shorter carbon chain.

Interestingly, the addition of metal-containing phthalocyanines to the epoxy resin [37] leads to a noticeable improvement of the coating. Phthalocyanines, as it were, heal defects in the coating and prevent diffusion of corrosive anions to the metal surface. 
Of great interest is also the "double-decker" phthalocyanines (sandwiches) [38], when two phthalocyanine molecules are retained, for example, by the lanthanide cation Ln, whose ionic size does not allow it to enter the $\mathrm{N}_{4}$ plane. The adsorption of such molecules significantly reduces the access of water to the surface of the steel, enhances the corrosion resistance and increases the adhesion of the coating.

A complex coating on a steel electrode was performed using pulsed laser deposition $[39,40]$. Mixed thin layers of pseudobinary oxide $\mathrm{Zn}_{3} \mathrm{Ta}_{2} \mathrm{O}_{6}$ or $\mathrm{Zn}_{3} \mathrm{Nb}_{2} \mathrm{O}_{8}$ and meso-tetra (4pyridyl) zinc porphyrin, which are believed to form self-assembled nanoparticles, and which have a good protective effect $(66.6 \%)$ in a $0.1 \mathrm{M} \mathrm{NaCl}$ solution.

Some porphin derivatives were used as corrosion inhibitors for J55 [41] and N80 [42] steels in "sweet solutions" $(3.5 \% \mathrm{NaCl})$ saturated with $\mathrm{CO}_{2}$. Studies have shown that the protective effect increases with increasing concentration of porphyrin, but decreases with increasing temperature. In $[43,44]$, the anticorrosion properties of nanocomposite coatings (based on porphyrins in $20 \% \mathrm{Na}_{2} \mathrm{SO}_{4}$ solution) applied by spraying were studied. Spraying solutions were prepared by the following method: mixture $\boldsymbol{A}$ was prepared by dissolving $0.2 \mathrm{~g}$ of $\mathrm{Na}_{4} \mathrm{TFP}$ (tetrakis (1-methyl-4-pyridyl)- $21 H, 23 H$-porphin-tetra- $p$-phosylate) (salt $\mathrm{P}$ ) in $40 \mathrm{ml}$ of $10 \% \mathrm{KOH}$, mixture $\boldsymbol{B}$ by dissolution $0.2 \mathrm{~g}$ of Na 4 TFP in $40 \mathrm{ml}$ of $10 \% \mathrm{H}_{2} \mathrm{SO}_{4}$, mixture $\boldsymbol{C}$ by dissolving $0.2 \mathrm{~g}$ of $\mathrm{H}_{2} \mathrm{TPP}$ in benzonitrile. It was determined that coatings based on mixture $\boldsymbol{A}$ slightly reduce the corrosion rate, mixture $\boldsymbol{B}$, on the contrary, accelerates the corrosion process, and mixture $\boldsymbol{C}$ forms a stable passive anticorrosion layer, significantly reducing the corrosion rate of steel, which is confirmed by direct corrosion tests in a chamber of neutral salt fog, and by the polarization curve method.

The use of the second layer of bis [trimethoxysilylpropylamine] along with copper phthalocyanine deposited on mild steel at 120 and $150^{\circ} \mathrm{C}$ led to a significant (almost an order of magnitude) improvement of the protective properties of the film [45]. Chinese researchers doped polyaniline with copper-phthalocyanine disulfonic acid in dimethylformamide [46]. The method of polarization potentiodynamic measurements, as well as EIS, showed the high protective properties of coatings formed on steel samples in a $3.5 \% \mathrm{NaCl}$ solution.

In [47], the adsorption of [2,4-di(1-methoxyethyl)deuteroporphyrin IX disodium salt] "dimegin" was studied; on the oxidized surface of St3 by the method of reflective ellipsometry, as well as by polarization curves in a borate buffer solution, $\mathrm{pH}$ 7.4. According to the reflective ellipsometry the adsorption proceeds by the chemical mechanism, since the values of the free energy of adsorption were $43.3 \pm 2.6 \mathrm{~kJ} / \mathrm{mol}$. Isotherms are adequately described by the complete Temkin equation [48]:

$$
\theta=\frac{1}{f} \ln \frac{1+n^{-1} B_{\text {max }}\left(C-C_{0}\right)}{1+n^{-1} B_{\text {min }}\left(C-C_{0}\right)}
$$

According to the electrochemical studies, the introduction of dimegin into a solution with a concentration of $10-30 \mu \mathrm{M}$ reduces the critical passivation current density on the 
anodic polarization curve of steel and complicates the local depassivation of the electrode. So, at $C_{\text {ing }}=30 \mu \mathrm{M}$, the current density decreases almost 4 times, and the difference in pitting potentials was $0.16 \mathrm{~V}$. The effect of the modification of the steel surface with dimegin with subsequent adsorption of BTA is also shown. Thus, the preliminary adsorption of dimegin makes it possible to significantly increase the adsorption of BTA, which is confirmed by a significant increase in the free energy of adsorption from 19.2 to $45.1 \mathrm{~kJ} / \mathrm{mol}$.

\section{Corrosion inhibition of aluminum and its alloys}

In [49], 1,(4)-tetrakis[(2-mercapto) pyridine]phthalocyanine(I) and 2,3-octakis[(2mercapto)pyridine]phthalocyanine(II) were studied as corrosion inhibitors for aluminum in $0.1 \mathrm{M} \mathrm{HCl}$ solution using the methods of polarization curves and electrochemical impedance. The results of the study showed that the efficiency of inhibition increases with increasing concentration of the inhibitor. The maximum degree of protection $\mathrm{Z}$ was determined for the first phthalocyanine and amounted to $83 \%$, this value is consistent when using both methods. However, with increasing temperature, the protective effect decreases, which is associated with the physical adsorption of inhibitors on the surface of aluminum. Adsorption obeys the Langmuir isotherm, which suggests that adsorbed molecules do not interact with other molecules.

Dibetsoe et al. [50] presented a study of a number of macroheterocyclic inhibitors for aluminum in $1.0 \mathrm{M} \mathrm{HCl}$. Four phthalocyanines (Pc) were studied as inhibitors, namely: 1,4,8,11,15,18,22,25-octabutoxy-29H，31H-phthalocyanine (Pc1); 2,3,9,10,16,17,23,24octakis(octyloxy)-29H,31H-phthalocyanine (Pc2); 2,9,16,23-tetratert-butyl-29H,31Hphthalocyanine (Pc3) and 29H,31H-phthalocyanine (Pc4), and three naphthalocyanines, namely: 5,9,14,18,23,27,32,36-octabutoxy-2,3-naphthalocyanine (nPc1); 2,11,20,29-tetratert-butyl-2,3-naphthalocyanine (nPc2) and 2,3-naphthalocyanine (nP3). All studied compounds demonstrated high inhibition efficiency, which decreases with increasing temperature from 30 to $70^{\circ} \mathrm{C}$, that is confirmed by both polarization and gravimetric methods. However, Pc1 was the best among phthalocyanines $(\mathrm{Pc})$, and $\mathrm{nPc} 3$ among naphthalocyanines (nPc). The thermodynamic and kinetic parameters of adsorption on the surface of aluminum have shown that in this case different mechanisms can be realized (both physical adsorption and chemisorption). When $0.1 \% \mathrm{KI}$ was added to the inhibitor solution, the protection efficiency increased. The authors calculated the synergy parameter by the formula of Aramaki and Hackerman [51]:

$$
S_{\mathrm{I}}=\frac{1-I_{1+2}}{1-I_{1+2}^{\prime}}
$$

where $I_{1+2}=I_{1}+I_{2}, I_{1}-$ inhibition efficiency only of KI, $I_{2}$ is the inhibition efficiency of Pc or nPc used as inhibitors without KI, and $I_{1+2}^{\prime}$ is the inhibition efficiency of Pc or nPc in combination with KI, and they received $S_{\mathrm{I}}>1$. This points out synergistic interaction between the studied molecules and iodide ions $I^{-}$. Judging by the results of studies of the 
potentiodynamic polarization of aluminum, $\mathrm{Pc}$ and $\mathrm{nPc}$ are mixed-type corrosion inhibitors, both in the absence and with the addition of KI. It should be noted that in quantum chemical calculations the efficiency of phthalocyanines correlates well with the position of the highest occupied molecular orbital: the higher it is, the easier the molecule transfers the electron to the free $d$-orbital of the metal to form a strong bond.

Polarisation potentiodynamic measurements and EIS were used to study copper $\left(2^{+}\right)$ phthalocyanine and copper $\left(2^{+}\right)$tetranitrophthalocyanine as an inhibitor for aluminum in $0.1 \mathrm{M} \mathrm{HC1}$ [52]. It was shown that both reagents suppress the cathodic and anodic processes, and the second one makes it worse, that the authors associate with spatial difficulties.

Complex phthalocyanine: tetrakis [(benzo[ $d]$ thiazol-2-yl-thio)phthalo-cyaninato]gallium(III) chloride (ClGaBTThioPc) [53] was investigated as a corrosion inhibitor for aluminum in $1.0 \mathrm{M}$ hydrochloric acid. The introduction of $10^{-7} \mathrm{M} \mathrm{ClGaBTThioPc}$ has been shown to result in $81 \%$ protection. Based on the data of the IR spectra, it was concluded that the molecules are flat, which block the reaction centers on the aluminum surface, forming numerous coordination bonds with aluminum $p$-orbitals, thus preventing further metal oxidation. The corrosion inhibition of aluminum in $2.0 \mathrm{M}$ hydrochloric acid by cobalt tetrasulfophthalocyanine was studied using gas analysis, thermometry, and polarization potentiodynamic measurements [54]. It was shown that the inhibitory effect begins at a very low concentration of $10^{-7} \mathrm{M}$, but reaches a maximum at $C=2 \times 10^{-4} \mathrm{M}$.

\section{Corrosion inhibition of copper and other metals}

Lokesh et al. [55] studied the adsorption of cobalt(II) 5,10,15,20-tetrakis(2-aminophenyl) porphyrin $\left(\mathrm{Co}(\mathrm{II})\left(\mathrm{T}\left(o-\mathrm{NH}_{2}\right) \mathrm{PP}\right)\right.$ on the surface of copper, as well as the anticorrosion properties of the adsorbed layers in $0.1 \mathrm{M} \mathrm{Na}_{2} \mathrm{SO}_{4}$, studied by XPE and atomic force spectroscopies.

EIS studies have shown that the $Z$ value for copper with adsorbed porphyrin reaches $97 \%$, and the charge transfer resistance increases by almost 80 times. The authors propose a mechanism of adsorption and layer formation based on the similarity of the BTA macro heterocycle [56]. One of the stages of adsorption is the shift of the electron density from porphyrin rings and lone pairs of electrons of nitrogen atoms to free copper orbitals, and the second one is the formation of a bond due to the transfer of copper electrons to the free orbital $d_{\mathrm{z}} 2$ of the cobalt atom. The Tafel plots show a decrease in the value of the corrosion current density for the modified $\mathrm{Co}(\mathrm{II})\left(\mathrm{T}\left(o-\mathrm{NH}_{2}\right) \mathrm{PP}\right)$ electrode compared to the electrode without treatment.

Interesting data were obtained by Hu et al. [57], who studied the effect of 5,10,15,20tetraphenylporphyrin (TPP) on the AZ91D magnesium alloy in a $0.05 \% \mathrm{NaCl}$ solution. The results of electrochemical measurements and direct corrosion tests show that the degree of protection by TPP can reach $90 \%$. The TPP complex with dissolved $\mathrm{Mg}^{2+}$ forms a TPP-Mg compound through its nitrogen atoms and is deposited on the surface of the AZ91D alloy. Precipitated complex TPP-Mg mixes with the initial $\mathrm{Mg}(\mathrm{OH})_{2}$ film in the outer layer, 
significantly reducing the porosity of the surface film and thus reducing the corrosion of AZ91D alloy.

Kuznetsov et al. [58] studied the adsorption of [2,4-di(1-methoxyethyl) deuteroporphyrin IX disodium salt] - "dimegin" on the copper surface in a borate buffer solution pH 7.4 using the in situ ellipsometric method. Its inhibitory and passivating properties were estimated by registering the polarization curves. Using the method of reflective ellipsometry, it was determined that adsorption proceeds by the chemical mechanism because the value of the free adsorption energy was found to be equal to $55.5 \mathrm{~kJ} / \mathrm{mol}$ for copper. Isotherms are adequately described by the complete Temkin equation. Polarization measurements showed that the introduction of dimegin shifts the potential of free corrosion to the region of more positive values. At $C_{\mathrm{inh}}=10 \mu \mathrm{M}$, the passivation of the copper electrode is observed, and with an increase in concentration up to $50 \mu \mathrm{M}$, the difference in local depassivation potentials is $160 \mathrm{mV}$.

Using the XPS method, it was shown that a dimegin molecule forms a monomolecular layer on the surface of copper oxide, and the plane of the molecule is at an angle to the surface. In this case, the dimegin molecule is fixed on the surface due to the oxygen atoms of two adjacent carboxyl groups.

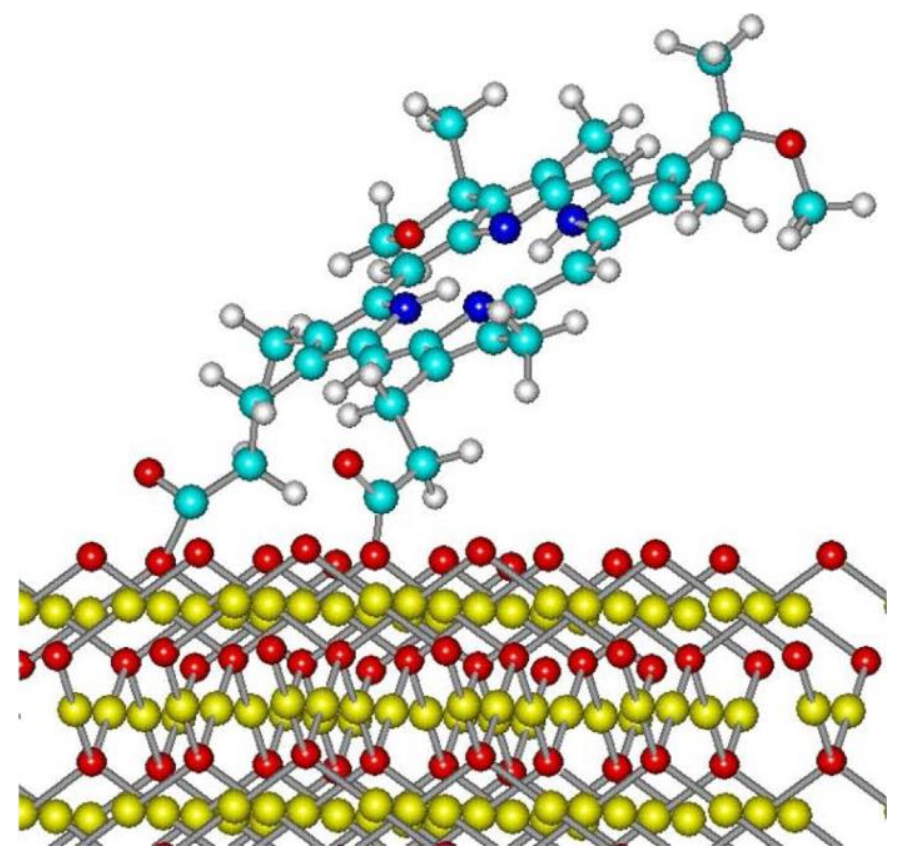

Figure 3. Probable fixation of dimegin on the surface of copper oxide.

Of great importance for predicting the protective ability of porphyrins in neutral environments is the work of Lokesh [59]. The authors investigated two porphyrin isomers: $5,10,15,20$-tetrakis-(2-aminophenyl)porphyrin $\left(\mathrm{Co}(\mathrm{II})\left(\mathrm{T}\left(o-\mathrm{NH}_{2}\right) \mathrm{PP}\right)\right)$, in which the amino group is in the ortho position, and 5,10,15,20-tetrakis-(4-aminophenyl)porphyrin $\left(\mathrm{Co}(\mathrm{II})\left(\mathrm{T}\left(p-\mathrm{NH}_{2}\right) \mathrm{PP}\right)\right)$, where $-\mathrm{NH}_{2}$ are in the para position. According to the results of 
Raman spectroscopy, the peak intensities are higher for $\mathrm{Co}(\mathrm{II})\left(\mathrm{T}\left(o-\mathrm{NH}_{2}\right) \mathrm{PP}\right)$, which indicates a larger number of adsorbed molecules on the gold surface.

The experiments carried out on an atomic force microscope showed an increase in the roughness of the gold surface from $15 \mathrm{~nm}$ to 79 and $37 \mathrm{~nm}$, modified by $\mathrm{Co}(\mathrm{II})\left(\mathrm{T}\left(o-\mathrm{NH}_{2}\right) \mathrm{PP}\right)$ and $\mathrm{Co}(\mathrm{II})\left(\mathrm{T}\left(p-\mathrm{NH}_{2}\right) \mathrm{PP}\right)$, respectively. However, it was found that porphyrin with an amino groups in the ortho position covers the surface completely and almost uniformly, unlike $\mathrm{Co}(\mathrm{II})\left(\mathrm{T}\left(p-\mathrm{NH}_{2}\right) \mathrm{PP}\right)$, which covers the surface only partially. According to EIS, both porphyrins increase the charge transfer resistance $R_{\mathrm{ct}}$. However, $R_{\mathrm{ct}}$ in the case of $\mathrm{Co}(\mathrm{II})(\mathrm{T}(o-$ $\left.\left.\mathrm{NH}_{2}\right) \mathrm{PP}\right)$ is almost 4 times higher than in the case of $\mathrm{Co}(\mathrm{II})\left(\mathrm{T}\left(p-\mathrm{NH}_{2}\right) \mathrm{PP}\right)$ : they amount to 3002 and $844 \mathrm{kOhm} \cdot \mathrm{cm}^{2}$, respectively.

In [60], direct corrosion tests in a heat and moisture chamber showed the high efficiency of 3,7,12,17-tetramethyl-8,13-divinyl-2,18-deuteroporphyrin (IX) (depocolin) to inhibit atmospheric corrosion of copper. The time before the appearance of the first corrosion lesions on samples aged in a solution of depokolin with $C_{\mathrm{inh}}=2 \mathrm{mM}$ for 5 min significantly exceeds the time for samples without treatment, 22 days and 1 day, respectively.

The adsorption of this protoporphyrin was studied by XPS. According to the results of which the authors suggest that adsorption proceeds according to the chemical mechanism due to the formation of a bond between the carboxyl groups of the molecule and the metal surface, which is a thin layer of cuprite. According to the results of polarization potentiodynamic measurements, the introduction of depocolin into a borate buffer solution containing $10 \mathrm{mM} \mathrm{NaCl}$ shifts the free corrosion potential to a region of more positive values. At $C_{\mathrm{inh}}=0.1 \mathrm{mM}$, a decrease in the current density of the anodic polarization curve is observed, and with an increase to $0.25 \mathrm{mM}$, local depassivation of the copper electrode is complicated.

In [61], adsorption and polarization potentiodynamic studies of two protoporphyrins: depocolin and dimegin, on the surface of nickel in neutral solutions are presented. Polarization measurements showed that both porphyrins complicate local depassivation of nickel in a chloride solution, however, dimegin is a more effective inhibitor, since at lower concentrations of $50 \mu \mathrm{M}$ it shifts $E_{\mathrm{pt}}$ by $190 \mathrm{mV}$, while depocolin at $C_{\mathrm{inh}}=500 \mu \mathrm{M}$ shifts it by $60 \mathrm{mV}$.

The method of reflective ellipsometry showed the chemisorption nature of adsorption, so the free adsorption energy of dimegin was 54.8 and $75.3 \mathrm{~kJ} / \mathrm{mol}$ on the oxidized and reduced nickel surface, respectively. Isotherms are adequately described by the complete Temkin equation. According to the results of XPS, adsorption occurs due to the formation of a bond between the carboxyl groups of the molecule and the oxidized surface of nickel; the porphyrin core does not participate in the formation of bonds.

\section{Conclusion}

Considering the accumulated amount of work on the study of macrocyclic compounds as corrosion inhibitors, we can conclude that they can be successfully used to protect metals 
and alloys in various environments. They form self-assembled nanosized layers that prevent the access of aggressive components of the medium to the metal surface. Quite often, the efficiency of protection increases if the center of a molecule is occupied by a transition metal cation. The addition of various groups along the periphery of the molecule, which enhance its interaction with the surface, leads to this as well.

One cannot fail to note the works in which the layered deposition of a macromolecule and then the second molecule is used, when the total effect is much higher than the summary for the same concentrations. The combination of various physical research methods and quantum chemical calculations should lead to a deeper understanding of the mechanism of formation of protective layers of macromolecules. The study of porphyrins, phthalocyanines and their derivatives as corrosion inhibitors can disclose many interesting points, and they will be more widely used in practice.

\section{Acknowledgments}

This work was supported by the State scientific program "Development of the fundamental scientific basis for the protective action of metal corrosion inhibitors in gas and condensed media, nanocomposites, paintwork and conversion coatings", No. 01201353193.

\section{References}

1. Yu.I. Kuznetsov, Organic inhibitors of corrosion of metals, Plenum Press, New York, 1996, 283. doi: 10.1007/978-1-4899-1956-4

2. Yu.I. Kuznetsov and L.P. Kazansky, Physicochemical aspects of metal protection by azoles as corrosion inhibitors, Usp. Khim., 2008, 77, no. 3, 227-241. doi: 10.1070/RC2008v077n03ABEH003753

3. A.A. Aksüt and S. Bilgiç, The effect of amino acids on the corrosion of nickel in $\mathrm{H}_{2} \mathrm{SO}_{4}$, Corros. Sci., 1992, 33, no. 3, 379-387. doi: 10.1016/0010-938X(92)90067-D

4. W. Yang and W.J. Mortier, The use of global and local molecular parameters for the analysis of the gas-phase basicity of amines, J. Am. Chem. Soc., 1986, 108, no. 19, $5708-$ 5711. doi: $10.1021 / \mathrm{ja} 00279 \mathrm{a} 008$

5. A. Frignani, C. Monticelli and G. Trabanelli, Inhibition of acid corrosion of nickel by acetylenic alcohols, Br. Corr. J., 1998, 33, no. 1, 71-75. doi: 10.1179/ 000705998798483508

6. J. Sam, J. Abraham, T. Sajini and J.J. Ajith, Corrosion inhibition properties of 1,2,4hetrocyclic systems: electrochemical, theoretical and Monte Carlo simulation studies, Egypt. J. Pet., 2017, 26, no. 3, 721-732. doi: 10.1016/j.ejpe.2016.10.005

7. M. Abdallah, H.E. Megahed, M.M. Elnager, E.M. Mabrouk and D. Radwan, Pitting corrosion of nickel alloys and its inhibition by some dihydrazide derivatives, Bull. Electrochem., 2003, 19, no. 6, 245-254.

8. M. Finsgar and I. Milosev, Inhibition of copper corrosion by 1,2,3-benzotriazole: a review, Corros. Sci., 2010, 52, no. 9, 2737-2749. doi: 10.1016/j.corsci.2010.05.002 
9. Yu.I. Kuznetsov, M.O. Agafonkina and N.P. Andreeva, Inhibition of copper dissolution in aqueous triazole solutions, Russ. J. Phys. Chem., 2014, 88, no. 4, 697-703 (in Russian). doi: $10.7868 / \mathrm{S} 0044453714040165$

10. Yu.I. Kuznetsov, Triazoles as a class of multifunctional corrosion inhibitors. A review. Part I. 1,2,3-Benzotriazole and its derivatives. Copper, zinc and their alloys, Int. J. Corros. Scale Inhib., 2018, 7, no. 3, 271-307. doi: 10.17675/2305-6894-2018-7-3-1

11. A.A. Chirkunov, Passivation of steel with some phosphorus-containing inhibitors, Korroz.: Mater., Zashch. (Corrosion: materials, protection), 2011, no. 1, 19-24 (in Russian).

12. Yu.I. Kuznetsov, Organic corrosion inhibitors: where are we now? A review. Part IV. Passivation and the role of mono- and diphosphonates, Int. J. Corros. Scale Inhib., 2017, 6, no. 4, 384-427. doi: 10.17675/2305-6894-2017-6-4-3

13. M.R. Tarasevich, K.A. Radyushkina and V.A. Bogdanovskaya, Elektrokhimiya porfirinov (Electrochemistry of porphyrins), Nauka, Moscow, 1991, p. 310 (in Russian).

14. M. Luciano and C. Brückner, Modifications of porphyrins and hydroporphyrins for their solubilization in aqueous media, Molecules, 2017, 22, 980. doi: $10.3390 /$ molecules 22060980

15. J.M. Gottfried, Surface chemistry of porphyrins and phthalocyanines, Surf. Sci. Reports, 2015, 70, 259-379. doi: 10.1016/j.surfrep.2015.04.001

16. F.R. Longo, J.J. DeLuccia and V.S. Agarwala, Proc. 6th European Symposium on "Corrosion Inhibitors", Univ. Ferrara, 1985, 155-166.

17. V.S. Agarwala, Proc. Int. Cong. Metal. Corros., 1984, 1, 380.

18. I.V. Aoki, I.C. Guedes and S.L.A. Maranhao, Copper phthalocyanine as corrosion inhibitor for ASTM A606-4 steel in 16\% hydrochloric acid, J. Appl. Electrochem., 2002, 32, 915-919. doi: 10.1023/A:1020506432003

19. S.L.A. Maranhao, I.C. Guedes, F.J. Anaissi, H.E. Toma and I.V. Aoki, Electrochemical and corrosion studies of poly(nickel-tetraaminophthalocyanine) on carbon steel, Electrochim. Acta, 2006, 52, 519-526. doi: 10.1016/j.electacta.2006.05.033

20. S. Hettiarachchi, Y.W. Chan, R.B. Wilson and V.S. Agarwala, Phthalocyanine and polyphthtalocyanine coatings for corrosion protection of metals, J. Mat. Res. Soc. Symp. Proc., 1988, 125, 321-327.

21.P. Zhao, L. Niu, L. Huang and F. Zhang, Electrochemical and XPS investigation of phthalocyanine oligomer sulfonate as a corrosion inhibitor for iron in hydrochloric acid, J. Electrochem. Soc., 2008, 155, no.10, 515-520. doi: 10.1149/1.2967187

22. P. Zhao, Q. Liang and Y. Li., Electrochemical, SEM/EDS and quantum chemical study of phthalocyanines as corrosion inhibitors for mild steel in $1 \mathrm{~mol} / \mathrm{l} \mathrm{HCl}$, Appl. Surf. Sci., 2005, 252, 1596-1607. doi: 10.1016/j.apsusc.2005.02.121

23. M. Davoodi and M. Nasr-Esfahani, Enhancement of the anticorrosion efficient of hybrid nanostructure coating using copper phthalocyanine self-assembled monolayers, Prot. Met. Phys. Chem. Surf., 2016, 52, no. 1, 149-155. doi: 10.1134/S207020511601007X 
24. M.A. Quraishi and J. Rawat, A review on macrocyclic as corrosion inhibitors, Corros. Rev., 2011, 19, no. 3-4, 273. doi: 10.1515/CORRREV.2001.19.3-4.273

25. J.C. Valle-Quitana, G.F. Dominguez-Patiño and J.G. Gonzalez-Rodriguez, Corrosion inhibition of carbon steel in $0.5 \mathrm{M} \mathrm{H}_{2} \mathrm{SO}_{4}$ by phtalocyanine blue, ISRN Corros., 2014, 945645. doi: $10.1155 / 2014 / 945645$

26. Y. Feng, S. Chen, W. Guo, G. Liu, H. Ma and L. Wu, Electrochemical and molecular simulation studies on the corrosion inhibition of 5,10,15,20-tetraphenylporphyrin adlayers on iron surface, Appl. Surf. Sci., 2007, 253, 8734-874. doi: 10.1016/j.apsusc.2007.04.062

27. Y. Feng, S. Chen, W. Guo, Y.Zhang and G. Liu, Inhibition of iron corrosion by 5,10,15,20-tetraphenylporphyrin and 5,10,15,20-tetra-(4-chlorophenyl)porphyrin adlayers in $0.5 \mathrm{M} \mathrm{H}_{2} \mathrm{SO}_{4}$ solutions, J. Electroanal. Chem., 2007, 602, 115-122. doi: 10.1016/j.jelechem.2006.12.016

28. B. Meyer-Roscher, T. Siemens and H. Brockmann, Tetraphenylporphyrinsas coupling reagents and corrosion inhibitors, Adv. Mater, 1992, 4, no. 7/8, 496-498. doi: 10.1002/adma.19920040709

29. G. Fagadar-Cosma， B.O. Taranu， M. Birdeanu， M. Popescu and E. Fagadar-Cosma, Influence of 5,10,15,20-tetakis(4-pyridyl)-21 $\mathrm{H}, 23 \mathrm{H}$-Porphyrin on the corrosion of steel in aqueous sulfuric acid, J. Nanomater. and Biostructures, 2014, 9, no. 2, 551-557.

30. G. Fagadar-Cosma, E. Fagadar-Cosma, I. Popa and I. Taranu, Electrochemical and spectroscopic studies of 5,10,15,20-tetrakis(4-hydroxyphenyl)-21 $\mathrm{H}, 23 \mathrm{H}$-porphine, Chem. Bull. "POLITEHNICA" Univ. (Timişoara), 2007, 52, no. 1-2, 109-112.

31. I. Popa, E. Fagadar-Cosma, B-O. Taranu, M. Birdeanu, G. Fagadar-Cosma and I. Taranu, Corrosion protection efficiency of bilayer porphyrin-polyaniline film deposited on carbon steel, Macromol. Symp., 2015, 352, 16-24. doi: 10.1002/masy.201400137

32. A. Singh, Y. Lin, M.A. Quraishi, L.O. Olasunkanmi, O.E. Fayemi, Y. Sasikumar, B. Ramaganthan, I. Bahadur, I.B. Obot, A.S. Adekunle, M.M. Kabanda and E.E. Ebenso, Porphyrins as corrosion inhibitors for $\mathrm{N} 80$ steel in $3.5 \% \mathrm{NaCl}$ solution: electrochemical, quantum chemical, QSAR and Monte Carlo simulations studies, Molecules, 2015, 20, 15122-15146. doi: 10.3390/molecules200815122

33. A. Singh, M. Talha, X. Xu, Z. Sun and Y. Lin, Heterocyclic corrosion inhibitors for J55 steel in a sweet corrosive medium, ACS Omega, 2017, 2, 8177-8186. doi: 10.1021/acsomega.7b01376

34. M.A. Deyab, G. Meleb, A.M. Al-Sabagh, E. Bloise, D. Lomonaco, S.E. Mazzetto and C.D.S. Clemente, Synthesis and characteristics of alkyd resin/M-Porphyrins nanocomposite for corrosion protection application, Prog. Org. Coat., 2017, 105, 286290. doi: 10.1016/j.porgcoat.2017.01.008 
35. H.I. Beltran, R. Esquivel, M. Lozada-Cassou, M.A. Dominguez-Aguilar, A. SosaSanchez, J.L. Sosa-Sanchez, H. Hopfl, V. Barba, R. Luna-Garcia, N. Farfan and L.S. Zamudio-Rivera, Nanocap-shaped tin phthalocyanines: synthesis, characterization, and corrosion inhibition activity, Chem. Eur. J., 2005, 11, 2705-2715. doi: 10.1002/chem.200400955

36. H.I. Beltran, R. Esquivel, A. Sosa-Sanchez, J.L. Sosa-Sanchez, H. Ho, V. Barba, N. Farfan, M.G. Garcia, O. Olivares-Xometl and L.S. Zamudio-Rivera, Microwave assisted stereoselective synthesis of cis-substituted tiniv phthalocyanine dicarboxylates. application as corrosion inhibitors, Inorg. Chem., 2004, 43, 3555-3557. doi: $\underline{10.1021 / \mathrm{ic} 049634 \mathrm{n}}$

37. M.A. Deyab, A. De Riccardis and G. Mele, Novel epoxy/metal phthalocyanines nanocomposite coatings for corrosion protection of carbon steel, J. Mol. Liq., 2016, 220, 513-517. doi: 10.1016/j.molliq.2016.04.115

38. M.A. Deyab, R. Słota, E. Bloise and G. Mele, Exploring corrosion protection properties of alkyd lanthanide bis-phthalocyanine nanocomposite coatings, RSC Adv., 2018, 8, 1909-1916. doi: 10.1039/C7RA09804A

39. M. Birdeanu, A.V. Bîrdeanu, M. Vaida, D. Milovanovic, A. Lascu and E. FagadarCosma, Corrosion behaviour of ZnTa2O6 pseudobinary oxide, zinc meso-tetra(4pyridyl) porphyrin (ZnTPyP) and hybrid ZnTa2O6/ZnTPyP layers deposited by PLD, Phys. Scr., 2019, 94, no. 7. doi: 10.1088/1402-4896/ab0857

40. M. Birdeanu, A-V. Bîrdeanu, I. Popa, B. Taranu, F. Peter, I. Creanga, A. Palade and E. Fagadar-Cosma, Comparative research regarding corrosion protective effect of different sandwich type nanostructures obtained from porphyrins and pseudo-binary oxides by changing the deposition order, NANOCON 2014, Brno, Czech Republic, EU, 262-267.

41. A. Singh, Y. Lin, K.R. Ansari, M.A. Quraishi, E.E. Ebenso, S. Chen and W. Liu, Electrochemical and surface studies of some porphines as corrosion inhibitor for J55 steel in sweet corrosion environment, Appl. Surf. Sci., 2015, 359, 331-339. doi: 10.1016/j.apsusc.2015.10.129

42. J. Wang, Y. Lin, A. Singh and W. Liu, Investigation of some porphyrin derivatives as inhibitors for corrosion of $\mathrm{N} 80$ steel at high temperature and high pressure in $3.5 \% \mathrm{NaCl}$ solution containing carbon dioxide, Int. J. Electrochem. Sci., 2018, 13, 11961-11973. doi: $10.20964 / 2018.12 .52$

43. A.-E. Segneanu, I. Balcu, N. Vlatanescu, Z. Urmosi and C.A. Macarie, Comparative study of porphyrin systems used as corrosion inhibitors, Corros. Resist., 2012, 175-188. doi: $10.5772 / 32829$

44. I. Balcu, A. Ivan, A.-E. Segeneanu, A.C. Macarie, Z. Urmosi and V.N. Vlatanescu, Study of multifunctional nanocomposites (porphyrin systems) used as corrosion inhibitors, Proceedings of the 11th WSEAS International Conference on Sustainability in Science Engineering, 520-524. 
45.P.H. Suegama and I.V. Aoki, Electrochemical behavior of carbon steel pre-treated with an organo functional bis-silane filled with copper phthalocyanine, J. Braz. Chem. Soc., 2008, 19, no. 4, 744-754. doi: 10.1590/S0103-50532008000400019

46. X. Li, L. Xu, Y. Liu, T. Liao, M. Li and X. Cui, Preparation and corrosion properties of polyaniline doped with copper phthalocyanine disulfonic acid, J. of Chinese Soc. Corros. Prot., 2016, 36, no. 4, 306-312. doi: 10.11902/1005.4537.2015.149

47. Yu.I. Kuznetsov, M.O. Agafonkina, N.P. Andreeva and A.B. Solov'eva, Modification of iron surface by dimegin and adsorption of 1,2,3-benzotriazole, Prot. Met. Phys. Chem. Surf., 2010, 46, 743-747. doi: 10.1134/S2070205110070014

48. M.O. Agafonkina, N.P. Andreeva, Yu.I. Kuznetsov and S.F. Timashev, Substituted benzotriazoles as inhibitors of copper corrosion in borate buffer solutions, Russian J. of Phys. Chem. A, 2017, 91, 8, 1414-1421. doi: 10.1134/S0036024417080027

49. O.K. Ozdemir, A. Aytac, D. Atilla and M. Durmus, Corrosion inhibition of aluminum by novel phthalocyanines in hydrochloric acid solution, J. Mater. Sci., 2011, 46, 752-758. doi: $10.1007 / \mathrm{s} 10853-010-4808-6$

50. M. Dibetsoe, L.O. Olasunkanmi, O.E. Fayemi, S. Yesudass, B. Ramaganthan, I. Bahadur, A.S. Adekunle, M.M. Kabanda and E.E. Ebenso, Some phthalocyanine and naphthalocyanine derivatives as corrosion inhibitors for aluminium in acidic medium: experimental, quantum chemical calculations, QSAR studies and synergistic effect of iodide ions, Molecules, 2015, 20, 15701-15734. doi: 10.3390/molecules200915701

51.K. Aramaki and N. Hackermann, Inhibition mechanism of medium-sized polymethyleneimine, J. Electrochem. Soc., 1969, 116, 568-573. doi: 10.1149/1.2411965

52. T. Pesha, G.R. Monama, M.J. Hato, T.C. Maponya, M.E. Makhatha, K.E. Ramohlola, K.M. Molapo, K.D. Modibane and M.S. Thomas, Inhibition effect of phthalocyaninatocopper(ii) and 4-tetranitro(phthalo-cyaninato)copper(ii) inhibitors for protection of aluminium in acidic media, Int. J. Electrochem. Sci., 2019, 14, 137-149. doi: $10.20964 / 2019.01 .17$

53. N. Nnaji, N. Nwaji, J. Mack and T. Nyokong, Corrosion resistance of aluminum against acid activation: Impact of benzothiazole-substituted gallium phthalocyanine, Molecules, 2019, 24, 207. doi: 10.3390/molecules24010207

54. V.N. Sivasankara Pillai, J. Thomas and P.S. Harikumar, Inhibition of corrosion of aluminium in hydrochloric acid by cobalt tetrasulphophtalocyanine, Indian J. Chem. Techn., 1995, 2, 99-103. doi: 10.1007/s10853-010-4808-6

55. K.S. Lokesh, M. Keersmaecker, A. Elia, D. Depla, P. Duruel, P. Vandenabeele, S. Vlierberhe and A. Adriaens, Adsorption of cobalt (II) 5,10,15,20-tetrakis(2aminophenyl)-porphyrin onto copper substrates: Characterization and impedance studies for corrosion inhibition, Corros. Sci., 2012, 62, 73-82. doi: 10.1016/j.corsci.2012.04.037

56. M. Finšgar and I. Milošev, Inhibition of copper corrosion by 1,2,3-benzotriazole: a review, Corros. Sci., 2010, 52, no. 9, 2737-2749. doi: 10.1016/j.corsci.2010.05.002 
57.J. Hu, D. Huang, G. Zhang, G.-L. Song and X. Guo, Research on the inhibition mechanism of tetraphenylporphyrin on AZ91D magnesium alloy, Corros. Sci., 2012, 63, 367-378. doi: 10.1016/j.corsci.2012.06.021

58. Yu.I. Kuznetsov, M.O. Agafonkina, N.P. Andreeva and L.P. Kazansky, Adsorption of dimegin and inhibition of copper dissolution in aqueous solutions, Corros. Sci., 2015, 100, 535-543. doi: $10.1016 / j$. corsci.2015.08.028

59. K.S. Lokesh, M. Keersmaecker and A. Adriaens, Self assembled films of porphyrins with amine groups at different positions: Influence of their orientation on the corrosion inhibition and the electrocatalytic activity, Molecules, 2012, 17, 7824-7842. doi: 10.3390/molecules 17077824

60. O.Yu. Grafov, L.P. Kazansky, S.V. Dubinskaya and Yu.I. Kuznetsov, Adsorption of depocolin and inhibition of copper dissolution in aqueous solutions, Int. J. Corros. Scale Inhib., 2019, 8, no. 3, 549-559. doi: 10.17675/2305-6894-2019-8-3-6

61. O.Yu. Grafov, M.O. Agafonkina, N.P. Andreeva, L.P. Kazansky and Yu.I. Kuznetsov, Adsorption of depocolin and dimegin on nickel from neutral aqueous solutions, Prot. Met. Phys. Chem. Surf., 2019, 55, no. 7, 1304-1310. doi: 10.1134/S2070205119070074 